\title{
Kids With Altitude: Acute Mountain Sickness and Changes in Body Mass and Total Body Water in Children Travelling to $3800 \mathrm{~m}$
}

\author{
Matt Rieger, $\mathrm{MSc}^{1}$; Isabel Algaze, $\mathrm{MD}^{2}$; Adriana Rodriguez-Vasquez, $\mathrm{MD}^{2}$; Kurt Smith, $\mathrm{PhD}^{3}$; \\ Mike Stembridge, $\mathrm{PhD}^{4}$; Brianne Smith $^{3}$; Shlomit Radom-Aizik, $\mathrm{PhD}^{5}$; Alison McManus, $\mathrm{PhD}^{1}$ \\ ${ }^{1}$ School of Health and Exercise Sciences, University of British Columbia Okanagan, Kelowna, Canada; ${ }^{2}$ Department of Emergency Medicine, \\ University of California Irvine Medical Center, Orange, California; ${ }^{3}$ Cerebrovascular Health, Exercise, and Environmental Research Sciences \\ Laboratory, School of Exercise Sciences and Physical Health Education, University of Victoria, Victoria, Canada; ${ }^{4}$ Cardiff School of Sport and \\ Health Sciences, Cardiff Metropolitan University, Cardiff, United Kingdom; ${ }^{5}$ Pediatric Exercise and Genomics Research Center, University of \\ California Irvine School of Medicine, Irvine, California
}

Introduction-We explored the incidence of acute mountain sickness (AMS) and extravascular lung water (ELW) in children in relation to changes in body composition and peripheral blood oxygenation $\left(\mathrm{S}_{\mathrm{p}} \mathrm{O}_{2}\right)$ during 1 week of acclimatization to $3800 \mathrm{~m}$.

Methods-In a prospective cohort study, 10 children ( 7 female, ages 7-14 y) and 10 sex-matched adults (ages 23-44 y) traveled via automobile from sea level to $3000 \mathrm{~m}$ for 2 nights, followed by 4 nights at $3800 \mathrm{~m}$. Each morning, body mass and body water (bioelectrical impedance), $\mathrm{S}_{\mathrm{p}} \mathrm{O}_{2}$ (pulse oximetry), AMS (Lake Louise Questionnaire), and ELW (transthoracic echocardiography) were measured.

Results-No differences were found between children and adults in $\mathrm{S}_{\mathrm{p}} \mathrm{O}_{2}$ or ELW. At $3800 \mathrm{~m} 7$ of 10 children were AMS+ vs 4 of 10 adults. Among those AMS+ at $3800 \mathrm{~m}$, the severity was greater in children compared to adults $(5 \pm 1$ vs $3 \pm 0 ; P=0.005)$. Loss of body mass occurred more quickly in children (day 5 vs day 7$)$ and to a greater extent $(-7 \pm 3 \%$ vs $-2 \pm 2 \% ; P<0.001)$; these changes were mediated via a larger relative loss in total body water in children than in adults $(-6 \pm 5 \%$ vs $-2 \pm 2 \% ; P=0.027)$.

Conclusions-Children demonstrated a higher incidence of AMS than adults, with greater severity among those AMS+. The loss of body water and body mass at high altitude was also greater in children, albeit unrelated to AMS severity. In addition to awareness of AMS, strategies to maintain body weight and hydration in children traveling to high altitudes should be considered.

Keywords: high altitude, maturation, physiology, pulmonary artery pressure, peripheral oxygenation, pediatric

\section{Introduction}

High-altitude travel that was once exclusive to mountaineers, explorers, and scientists is becoming increasingly popular with travelers. Families are taking annual holidays to resorts in Colorado ( 2000-3500 m), trekking through the Himalayas ( 2500-5000 m), and visiting high mountain villages in both the European Alps and the Andes ( 2500-3500 m) on an ever-increasing scale. In each of these scenarios, children are more frequently accompanying their parents to altitudes up to and above $3000 \mathrm{~m}$, yet decades of high-altitude research have focused on the

Corresponding author: Matt Rieger, MSc; e-mail: matt.rieger@ubc.ca. Submitted for publication June 2021.

Accepted for publication November 2021. physiological responses to low-oxygen environments almost exclusively in adults. Upon traveling to $>3000 \mathrm{~m}$, $\sim 75 \%$ of adults have at least mild symptoms of acute mountain sickness (AMS), and a limited number of studies report either increased ${ }^{1-3}$ or similar ${ }^{4,5}$ incidence of AMS symptoms in children compared to adults; however, little is known about the integrative physiological acclimatization processes in children and the expression of AMS symptoms. The International Climbing and Mountaineering Federation medical commission consensus statement proposes that high-altitude travel is safe for children $>14$ wk old, ${ }^{6}$ yet descriptions of symptoms and guidelines for safe daily ascent rates (ie, 300-500 m.day ${ }^{-1}$ ) have been exclusively based on observations of adult trekkers. As such, there are limited 
scientific data on the related risks of traveling to altitude in children, so recommendations are broadly generalized and largely anecdotal.

In addition to differences in perception, stresses, and discomfort related to travel, ${ }^{1}$ children demonstrate large developmental differences in physiological factors relevant to high-altitude acclimation; specifically, these differences in children are demonstrated in ventilatory, ${ }^{7,8}$ autonomic, ${ }^{9}$ and cerebrovascular regulation. ${ }^{10-12}$ Collectively, these physiological differences may result in a phenotype in children that alters their acclimatization profile, both in magnitude and timing. Young children (6-9 y) display a larger increase in pulmonary artery systolic pressure than adolescents $(14-16 \mathrm{y})^{13}$ and adults after 18 to $40 \mathrm{~h}$ at $3450 \mathrm{~m},{ }^{14}$ which may explain reports of an increased occurrence of high altitude pulmonary edema in young populations. ${ }^{15-17}$ Nevertheless, no published data exist indicating whether these differences are maintained during periods of acclimatization or if they are preceded by increases in extravascular lung water. Renal excretion of bicarbonate enhances the ventilatory acclimatization to hypoxia in adults ${ }^{18-20}$ but can lead to loss of body water and dehydration. Young children are generally at a greater risk for dehydration than adults, ${ }^{21}$ which may be exacerbated during periods of travel and further increase the risk for AMS-like symptoms. Although peripheral blood oxygenation $\left(\mathrm{S}_{\mathrm{p}} \mathrm{O}_{2}\right)$ is a poor independent predictor of AMS, maturational differences throughout the oxygen transport cascade, ${ }^{22,23}$ combined with differences in ventilatory, autonomic, and cerebrovascular regulation in children, may thereby influence the development of AMS and the overall tolerance of high-altitude travel.

The aim of this work was to explore high altitude travel tolerance in a group of children and adults during a passive, staged ascent to a research facility at $3800 \mathrm{~m}$. We hypothesized that 1) children would be less tolerant of high-altitude than adults, based on symptoms associated with AMS and increased ELW; and 2) increases in symptoms of AMS in children would be associated with reductions in $\mathrm{S}_{\mathrm{p}} \mathrm{O}_{2}$ and total body water.

\section{Methods}

This study was approved by the clinical research ethics board of the University of British Columbia, as well as the institutional review board at University of California Irvine. All experimental protocols and procedures conformed to the standards set by the Canadian government tri-council policy statement for integrity in research, as well as the Declaration of Helsinki, except for registration in a database. A detailed verbal and written explanation of the measurements was provided to participants and parents/guardians before participation. All participants and parents provided written, informed consent, and child participants provided written assent.

Ten children and adolescents (ages 7-14 y, 7 female) and 10 sex-matched adults (ages 23-44 y) participated in this study. None had any pre-existing diagnosed medical conditions. All participants lived $<600 \mathrm{~m}$ above sea level and had not spent significant time ( $>1 \mathrm{~h}$ ) above $2000 \mathrm{~m}$ in the 5 mo prior, confirmed by parents/participants. All children had at least 1 biological parent included in the adult group; 3 of the adults were not biologically related to any of the children but provided a sex match between the 2 groups.

This study was part of a larger expedition investigating cardiac, ventilatory, and cerebrovascular acclimatization to high altitude in children and adults. All participants traveled to Irvine, California, $(25 \mathrm{~m}$ above sea level) for baseline testing. From Irvine, participants were driven $\sim 8 \mathrm{~h}$ to the Crooked Creek Station (White Mountain Research Center, $3000 \mathrm{~m}$ above sea level), where they spent 2 nights acclimatizing. This stop at $3000 \mathrm{~m}$ was included to minimize the adverse physiological effects of rapid ascent to high altitude, help the children overcome any travel discomfort, and habituate both the children and adults to the testing at high altitude. The group was then driven to the Barcroft Field Station (White Mountain Research Center, $3800 \mathrm{~m}$ ), where testing took place over the course of the next 5 d (Figure 1). All meals were provided by staff at each station and participants ate ad libitum. Caffeine and alcohol were restricted $12 \mathrm{~h}$ prior to testing, and participants were instructed to have light snacks only $4 \mathrm{~h}$ before testing. No acetazolamide or other altitude-related medications were taken by any of the participants before or during the trip. The team included researchers from 4 different institutions, 2 wilderness medicine physicians, parents of the children, and 3 individuals who served as activity coordinators for the children. Importantly, apart from self-determined vigorous exercise, there were no restrictions on activities for children or adults. Children were actively engaged in a wide range of games and activities throughout the trip, and participants were free to go on short hikes in the area surrounding the facilities after testing was completed each day. This model aimed to create an environment similar to other recreational family trips to higher altitudes.

At baseline and at the same time each morning before communal breakfast, measurements were taken of peripheral blood oxygenation, resting heart rate, bodyweight, and bioelectrical impedance for total body water. A questionnaire for AMS was also administered at this 


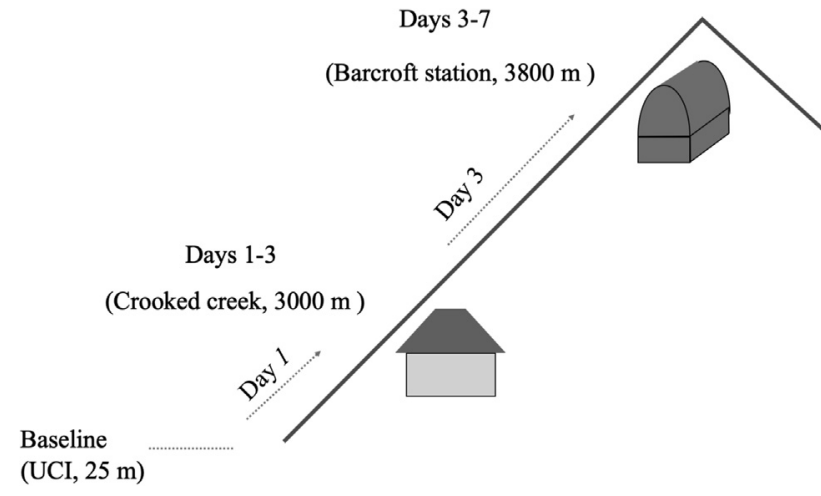

Figure 1. Chronological illustration of the trip timeline to the White Mountain Research Center. Baseline testing was performed at the University of California Irvine on the day before ascent.

time. In addition, on day 1 at Barcroft Station, the $\mathrm{S}_{\mathrm{p}} \mathrm{O}_{2}$ and AMS measurements were repeated $\sim 8$ to $10 \mathrm{~h}$ after arrival.

Pulse oximetry (Rad-5, Masimo) was used to measure $\mathrm{S}_{\mathrm{p}} \mathrm{O}_{2}$ and heart rate. Participants were seated upright in a chair for at least 2 min before measurement, and hands were warmed with an electric heating pad if necessary. $\mathrm{S}_{\mathrm{p}} \mathrm{O}_{2}$ and heart rate are reported as the average of 3 recordings during a 15 -s period once signals had stabilized.

Self-report of symptoms of AMS was recorded through a written 2018 Lake Louise questionnaire, with researchers present to ensure that the terminology used was clearly understood. The presence of AMS was identified by a headache score of at least 1 and by the 4 symptoms totaling a score of at least $3 .{ }^{24}$

Height and sitting height were measured with a portable stadiometer (Seca, Hamburg, Germany) during baseline testing at low altitude. Daily measurements of body mass and total body water were made using an electronic scale with foot-to-foot bioelectrical impedance (TBF-410, Tanita, Japan). For the children, the predicted offset to age at peak height velocity (ie, the predicted years prior to or past age at peak height velocity) was calculated as a marker of maturation. ${ }^{25}$

The presence of extravascular lung water was identified by examination of ultrasound lung comet artifacts at baseline, after 1 night at $3000 \mathrm{~m}$, and at 2 additional points over $4 \mathrm{~d}$ at $3800 \mathrm{~m}$ (after 2-4 h, 3 nights). Bilaterally, 4 windows were imaged using a commercially available ultrasound machine (Vivid Q, GE, Fairfield, CT, USA) with an M5-S 1.5 to $4.6 \mathrm{MHz}$ transducer. The number of B-line artifacts was manually counted from each image and recorded as a total comet tail score. The condensed 4-window view has been previously validated against the 8-window view for clinical purposes. ${ }^{26}$

The ActivPAL micro accelerometer (PAL Technologies Limited; Glasgow, Scotland, UK) was used to assess physical activity (steps per day). Participants wore the device on the anterior aspect of the right thigh, placed within a flexible nitrile sleeve and attached using Tegaderm Transparent Film (3M Health Care; St. Paul, MN, USA). Participants were asked to wear the device continuously for $7 \mathrm{~d}$ at baseline and throughout days 3 to 6 at high altitude. Day 7 was not included because this was spent being driven back to Irvine.

Descriptive statistics are presented as mean \pm SD. A Student's t-test was used to identify differences in descriptive characteristics at baseline. Analysis of the primary outcome variables (AMS symptoms, body weight, body water, $\mathrm{S}_{\mathrm{p}} \mathrm{O}_{2}$ ) was performed using a 2-way repeated measures analysis of variation (factors: time and age group). Similar analysis was performed on a change score from baseline where applicable. When necessary, interactions and main effects were deconstructed using ttests with Bonferroni correction. Linear regression was further used to test the relationships among weight change, AMS, and $\mathrm{S}_{\mathrm{p}} \mathrm{O}_{2}$ in each group. Statistical significance was set a priori at $P<0.05$, and all analyses were performed using SPSS (Version 25, SPSS; Chicago, IL).

\section{Results}

Participant characteristics are presented in Table 1. As expected, adults were taller and heavier and had a higher percent body fat and a lower percent total body water $(P<0.05$ for all).

Upon arrival at $3000 \mathrm{~m}$, total AMS scores were elevated compared to baseline in both children and adults

Table 1. Participant characteristics

\begin{tabular}{lcccrrrrr}
\hline & $n$ & $F / M$ & \multicolumn{1}{l}{$\begin{array}{l}\text { Age } \\
\text { range }(y)\end{array}$} & Age $(y)$ & Height $(\mathrm{cm})$ & Weight $(\mathrm{kg})$ & \multicolumn{1}{c}{$\begin{array}{l}\text { Body } \\
\text { fat }(\%)\end{array}$} & \multicolumn{1}{c}{$\begin{array}{l}\text { Total body } \\
\text { water }(\%)\end{array}$} \\
\hline Children & 10 & $7 / 3$ & $7-14$ & $9.8 \pm 2.5$ & $141 \pm 15$ & $34.5 \pm 9.8$ & $15 \pm 7$ & $60 \pm 4$ \\
Adults & 10 & $7 / 3$ & $23-44$ & $34.7 \pm 7.1^{a}$ & $171 \pm 6^{a}$ & $65.9 \pm 11.8^{a}$ & $23 \pm 9^{a}$ & $56 \pm 6^{a}$ \\
\hline
\end{tabular}

Values represent mean \pm SD.

${ }^{a}$ Significant $(P<0.05)$ difference between children and adults. 
A)

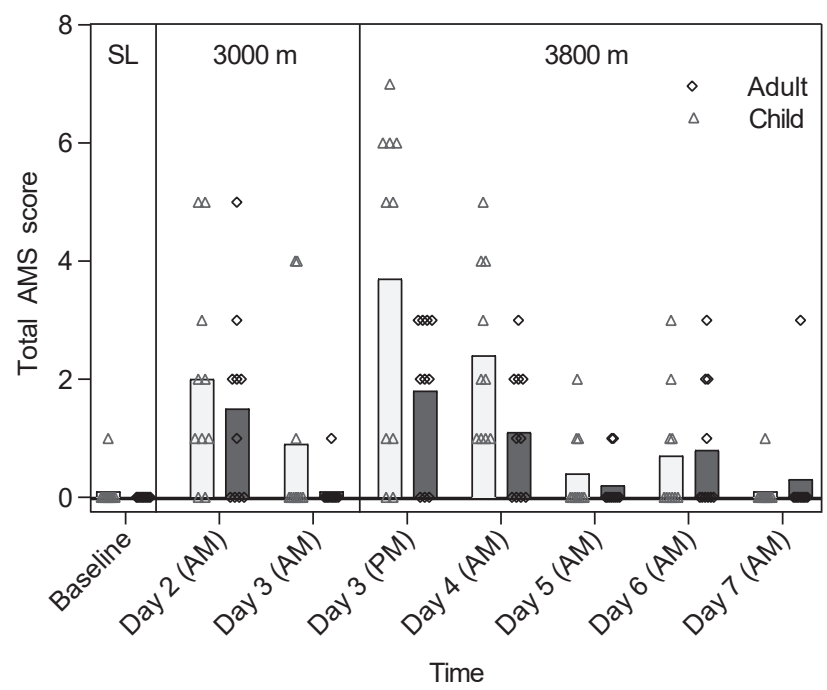

B)

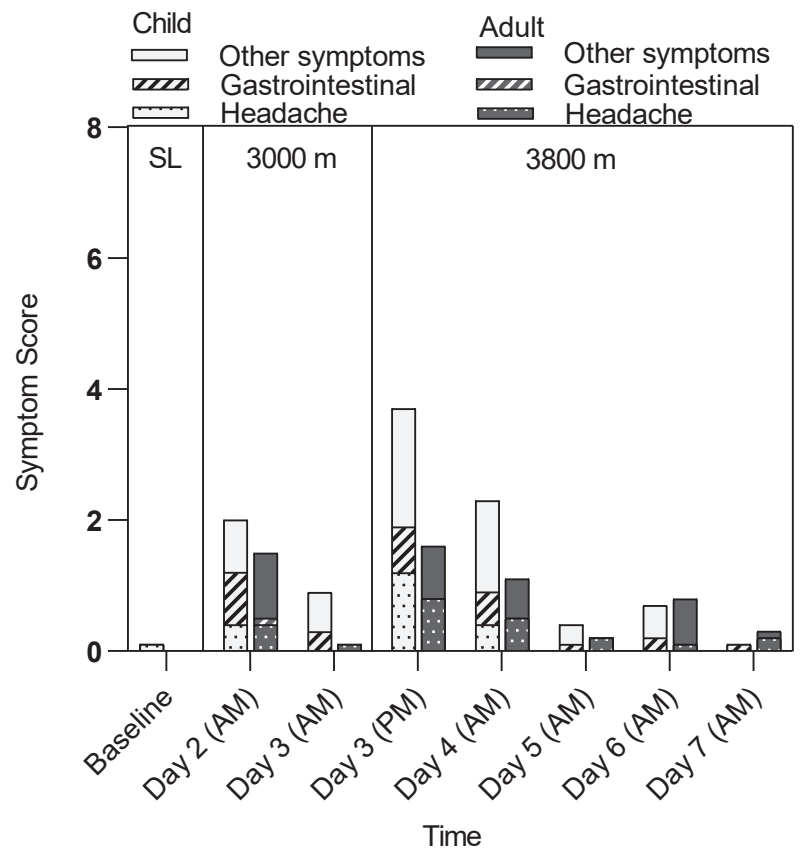

Figure 2. Acute mountain sickness score based on the 2018 Lake Louise scoring system in children and adults at sea level and at high altitude. (A) Total acute mountain sickness score. Significant main effects for age $(P=0.006)$ and time $(P<0.001)$ exist, but no interaction was found $(P=0.131)$. (B) Symptom-specific scores. "Other" represents fatigue, dizziness, and clinical functional score.

$(P<0.01)$ with no age by time interaction. A second increase in AMS score occurred in both groups on the evening of arrival at $3800 \mathrm{~m}(P<0.01)$, with a higher mean AMS score for the children, but this was not significant ( $4 \pm 1$ vs $2 \pm 1$, respectively; $P=0.07$ ). Importantly, although the sickest 3 adults each reported a total AMS score of 3 (mild AMS) on the first night at $3800 \mathrm{~m}, 6$ of
10 children reported a total AMS score of 5 or greater (moderate AMS, Figure 2A).

Symptom-specific AMS scores are reported in Figure 2B. Headache, fatigue, dizziness, and functional scores were similar at all times between children and adults, but nausea-related gastrointestinal symptoms were more severe in children on day 2 AM (first morning at 


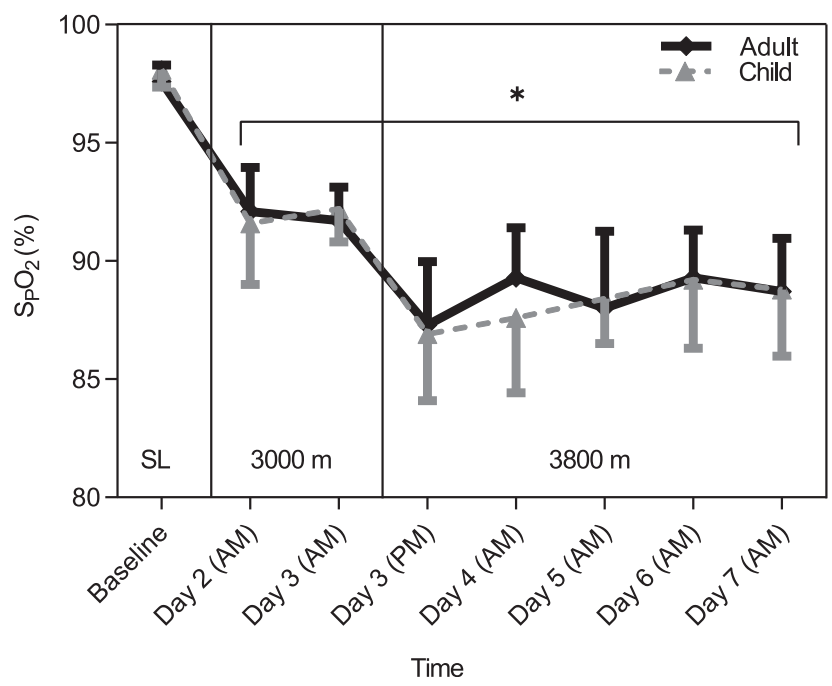

Figure 3. Peripheral oxygenation $\left(\mathrm{S}_{\mathrm{p}} \mathrm{O}_{2} \%\right)$ measured via finger pulse oximetry in children and adults during a 1 wk visit to high altitude. A significant main effect of time was observed $(P<0.01)$, but not for group $(P=0.70)$ or interaction $(P=0.86)$. No difference between groups was present at any time. $\mathrm{S}_{\mathrm{p}} \mathrm{O}_{2}$ was reduced at each altitude and tended to increase over the $5 \mathrm{~d}$ at $3800 \mathrm{~m}$. *Significant difference from baseline $(P<0.05)$.

$3000 \mathrm{~m}, P=0.005)$, day $3 \mathrm{PM}(+8 \mathrm{~h}$ after arrival at 3800 $\mathrm{m}, P<0.001$ ), and day $4 \mathrm{AM}$ (after 1 night at $3800 \mathrm{~m}$, $P=0.004)$. These differences subsided by the second morning at $3800 \mathrm{~m}$.

Peripheral oxygenation was reduced with each increase in altitude (Figure 3), with a slow recovery $(+2 \%$ in children, $+1 \%$ in adults; $P=0.005$ ) over the $5 \mathrm{~d}$ spent at $3800 \mathrm{~m}$. No age by time interaction was found, and there were no correlations between $\mathrm{S}_{\mathrm{p}} \mathrm{O}_{2}$ and AMS on any of the testing days.

At all points, children had a higher resting heart rate than adults; however, no age by time interaction was found. Resting heart rate increased with each increase in altitude (Table 2), but there was no difference between groups in either the absolute change or percent change at any time.

Only a small number of lung comets (observed comet tail score range $=0-3$ ) was identified in either group, with no differences between children and adults or across altitudes. The number of individuals with nonzero scores during each measurement is presented in Table 3. No individual displayed B-lines in more than 1 intercostal window.

For total body weight loss, an age by time interaction was found $(P<0.001)$. In the children, a reduction
$(-2 \pm 2 \%, P=0.02)$ in total body weight relative to baseline was observed by day 5 of travel $(3800 \mathrm{~m})$, and this reduction continued through to the final day of high altitude (day 7, $3800 \mathrm{~m}$ ), where total body weight was reduced by $8 \pm 3 \% \quad(P<0.001)$ compared to baseline (Figure 4, Panel A). In contrast, body weight was maintained within a much narrower range in the adults, where a significant change from baseline was only observable on the final day at high altitude $(-2 \pm 2 \% ; P=0.03)$. These changes appear to be driven by a larger reduction in total body water in children (Figure 4, Panel B), who had lost a significantly greater fraction of total body water by the final day of high altitude compared to adults $(-7 \pm 5 \%$ vs $-2 \pm 2 \%$, respectively; $P=0.03)$. In both children and in adults, no relationship was found between AMS and change in body weight or between AMS and change in body water on a day-to-day basis or over the course of the entire week.

Steps per day are reported in Table 4. To provide context to these data, day 3 included the drive from the Crooked Creek station to Barcroft Station; participants completed testing on days 3,4 , and 6 , and there was no testing on day 5. Participants instead went for a hike in the local area. The children achieved more daily steps

Table 2. Resting heart rate (beats $\cdot \mathrm{min}^{-1}$ ) over the course of $1 \mathrm{wk}$ at high altitude

\begin{tabular}{lcccccccc}
\hline & Baseline & Day 2 & Day 3 (AM) & Day 3 (PM) & Day 4 & Day 5 & Day 6 & Day 7 \\
\hline Children & $92 \pm 11^{a}$ & $101 \pm 11^{a}$ & $97 \pm 13^{a}$ & $103 \pm 14^{a}$ & $99 \pm 16^{a}$ & $96 \pm 13^{a}$ & $89 \pm 16^{a}$ & $90 \pm 15^{a}$ \\
Adults & $73 \pm 24$ & $78 \pm 23$ & $79 \pm 21$ & $82 \pm 24$ & $76 \pm 20$ & $74 \pm 76$ & $76 \pm 24$ & $77 \pm 23$ \\
\hline
\end{tabular}

Values represent mean \pm SD.

${ }^{a}$ Significant difference $(P<0.05)$ between children and adults. 
Table 3. Individuals demonstrating a positive identification of ultrasound lung comets (score $>0$ )

\begin{tabular}{|c|c|c|c|c|}
\hline & Baseline & Day 2 & Day 3 & Day 6 \\
\hline & Sea level & $3000 \mathrm{~m}$ & $3800 \mathrm{~m}$ & $3800 \mathrm{~m}$ \\
\hline Children & $1 / 10$ & $0 / 10$ & $1 / 10$ & $0 / 10$ \\
\hline Adults & $1 / 10$ & $1 / 10$ & $1 / 10$ & $1 / 10$ \\
\hline
\end{tabular}

than the adults at baseline and day 4 (Group; $P=0.02$, Table 4); however, analysis of the change from sea level baseline indicates no differences in the pattern or magnitude of change in steps per day at high altitude $(P=0.49)$.

\section{Discussion}

In this study, we observed subjective symptoms and objective physiological acclimatization in children and adults over a week-long stay at high altitude, including 5 $\mathrm{d}$ at $3800 \mathrm{~m}$. We report no differences in peripheral oxygenation or extravascular lung water at any time between the children and adults; however, the incidence of AMS was greater in children upon arrival at $3800 \mathrm{~m}$; children also experienced a significantly greater loss in total body water and total body weight by day 6 of high altitude. No relationship between either $\mathrm{S}_{\mathrm{p}} \mathrm{O}_{2}$ or extravascular lung water and AMS was found on any of the days.

Initial ascent to $3000 \mathrm{~m}$ elicited a comparable mean AMS score for children and adults. Despite no significant difference in the mean scores of AMS at this altitude, pooled data from the 2 mornings indicate that only 2 of 10 adults were AMS+ (total score $\geq 3$, including headache) at the first station, whereas 5 of 10 children were AMS+ on at least 1 of the first 2 mornings. Subsequently, upon ascent to the upper station, total mean AMS score tended to be greater in the children $(P=0.07)$; however, the current investigation was likely underpowered to detect significant differences. When the first night and first morning at $3800 \mathrm{~m}$ were both considered, 7 of 10 children were AMS+ vs only 4 of 10 adults. Furthermore, among those who were AMS+, the severity was worse in the children $(5 \pm 1)$ compared to the adults $(3 \pm 0 ; P=0.005)$. The increased incidence and severity of AMS observed in children was apparent after each increase in altitude and potentially was even underreported based on unmeasured observations of acute "waves" of sickness in the children in between structured times of testing. For example, 1 girl spent several hours (under close observation) with peripheral saturations between 68 and 75\% during night 1 at 3000 $m$ but woke up and reported a score of 0 on the Lake Louise questionnaire the next morning. It should be noted that her parents reported her as susceptible to snoring at night, and her peripheral oxygen saturation improved immediately once she transitioned from a fetal to a supine position and her airway was opened using a head tilt and chin lift maneuver. In multiple other cases, children became acutely incapacitated for several hours at a time with nausea and headaches, but they were subjectively fine by the time the next self-report questionnaire was submitted.

Although we provide evidence of increased AMS incidence within our cohort, previous reports comparing AMS in children and adults remain largely inconclusive. For example, in young children ages 6 mo to $5 \mathrm{y}$, the incidence of AMS was elevated compared to adults upon arrival at $3500 \mathrm{~m}$; however, no difference was observed between teenagers (ages 13-17 y) and adults. ${ }^{3}$ In a larger study composed of 20 father-child pairs (children aged 9-12 y), no difference in the cumulative incidence of AMS was reported; however, differences in the severity of symptoms were not considered. ${ }^{5}$ Children have primarily shown similar ${ }^{27-29}$ or increased incidence of $\mathrm{AMS}^{2,4,30-32}$ compared to adult control groups. However, to our knowledge only 1 study has shown a reduced susceptibility in AMS in children, after rapid ascent via train to $3500 \mathrm{~m}^{33}$

The current definition of AMS requires at least a mild headache, and we demonstrated comparable prevalence and severity of headache between children and adults; however, the presence of increased gastrointestinal symptoms in children without an increased headache score suggests that the etiology of high-altitude illness in children may present differently than in adults. Evidently, even the process of being away from home may trigger symptoms associated with AMS in children. In a study of 9- to $14-\mathrm{y}$-olds $(\mathrm{n}=405)$ attending summer camp at sea level in California, $21 \%$ reported symptom scores equating to a positive diagnosis of AMS, compared to $28 \%$ of similar-aged children who were AMS+ at an actual high altitude $(2835 \mathrm{~m})$ summer camp in Colorado. ${ }^{1}$ In the current investigation, all children had at least 1 parent present, which may reduce some of the distress associated with being away from home; however, it is possible that maturational differences exist in the perception and reporting of AMS symptoms. Despite this, similar scores were reported between groups at baseline, after families had already spent 1 night in a hotel at sea level.

Ascent to high altitude can be associated with a loss in body weight owing to a combination of high altitude-induced anorexia ${ }^{34}$ (and thus decreased energy intake), dehydration, increased physical activity energy 


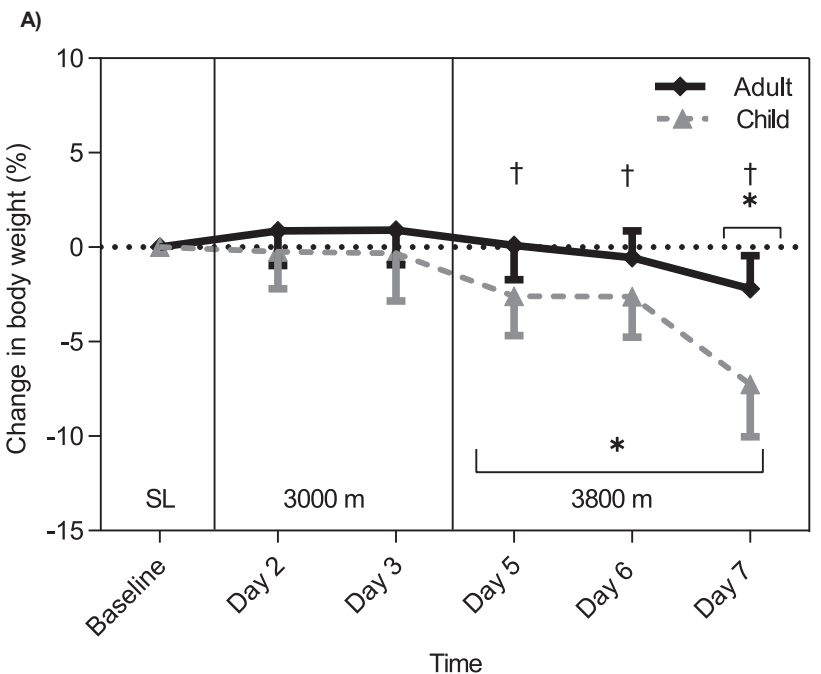

B)

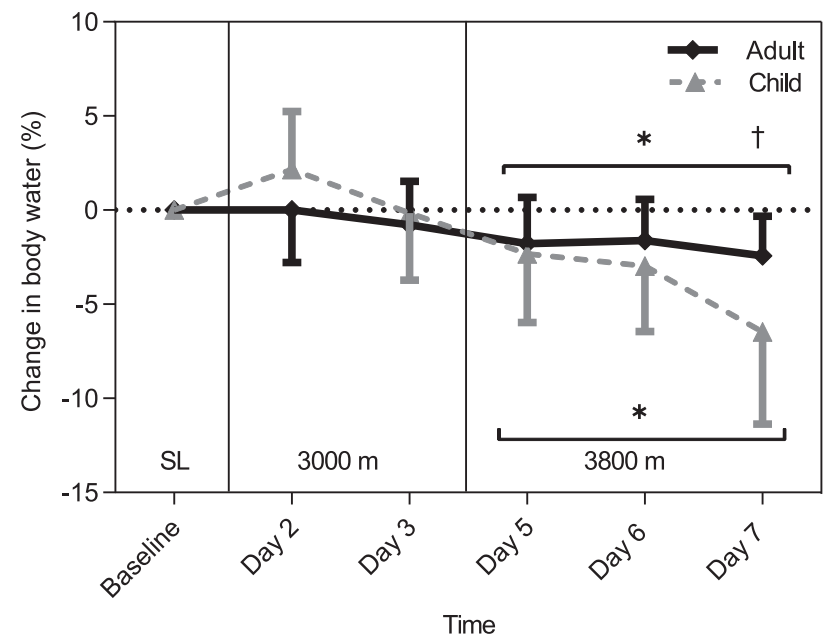

Figure 4. (A) Change in body weight and (B) change in body water during a 1-wk visit to high altitude in children and adults. Values represent mean \pm SD. *Significant difference from baseline $(P<0.05)$. ${ }^{\dagger}$ Difference between groups $(P<0.05)$.

expenditure, and increased metabolic rate. ${ }^{35-37}$ We found Importantly, this greater reduction in body weight in that despite an abundance of available food and drink, children was driven largely by a reduction in total body total body weight started to decline earlier in children water, with a relative water loss over 2 times greater compared to adults and to a larger degree. Specifically, than that of adults, which may also be in part related to by the final day at the upper station, children had lost children having a higher mean total body water percent $8 \%$ of their total body weight, vs $2 \%$ in the adults. compared to adults. ${ }^{38}$ Although water intake was not

Table 4. Daily step count at baseline and over the first 4 days at $3800 \mathrm{~m}$

\begin{tabular}{lllrrr}
\hline & Baseline & Day 3 & Day 4 & Day 5 & Day 6 \\
\hline Children & $16,787 \pm 3038$ & $13,174 \pm 3863$ & $16,755 \pm 4133$ & $23,037 \pm 5789$ & $15,777 \pm 7365$ \\
Adults & $9470 \pm 2400^{a}$ & $10,258 \pm 2454$ & $11,095 \pm 1612^{a}$ & $21,180 \pm 7219$ & $12,179 \pm 3454$ \\
\hline
\end{tabular}

Values represent mean \pm SD.

${ }^{a}$ Between-group difference $(P<0.05)$. 
measured, reports of inadequate water consumption are common in children, ${ }^{39,40}$ with the potential for even greater disruptions to water balance when traveling. On this trip, all participants were constantly prompted to have water with them at all times and were actively reminded to drink to ensure adequate fluid intake and avoid body water loss ${ }^{41}$; however, voluntary drinking does not always guarantee adequate hydration. ${ }^{42}$ Although renal function reaches maturity around 2 y of age based on glomerular filtration rates and urine concentrating and diluting capacity, ${ }^{43}$ it is not known whether maturational differences in bicarbonate excretion exist during acclimatization, which would have a profound impact on overall fluid status. Furthermore, at baseline, the children would be expected to have a 5 to $10 \%$ lower hemoglobin concentration compared to the adults. ${ }^{44}$ The greater loss in body water observed in children may in part be related to a larger reduction in plasma volume to increase arterial oxygen content through hematoconcentration.

Children are also at a greater risk of travel-related diarrhea than adults. ${ }^{45}$ We do report higher scores on gastrointestinal symptoms in children compared to adults; however, the current questionnaire only specifically asks about nausea and vomiting, and statistical differences between groups did not persist for the entire length of stay at $3800 \mathrm{~m}$. We cannot determine if a higher propensity for travelers' diarrhea in children could have been a cause of the larger change in body composition and total body water compared to adults, or if it is simply an independent additional risk that may exacerbate the complications associated with dehydration.

For the remainder of the total weight loss, we are unable to determine if this was due to decreased appetite and caloric intake in children, which may be related to the increased gastrointestinal symptoms in children, or due to a larger increase in energy expenditure. Our indicators of energy expenditure and metabolism, step count and heart rate, showed no age-related difference in the pattern of change from baseline, suggesting that the greater loss of body weight in children may be related to reductions in energy intake rather than expenditure. Additionally, we used a single-frequency $(50 \mathrm{kHz})$ bio impedance device for estimating body water. This high frequency is well suited to estimating intracellular, but not extracellular, water content. ${ }^{46}$ Body water analysis using low and high frequencies can estimate both intracellular and extracellular water compartments and therefore provide a more precise assessment of total body water. Future studies in children should consider compartmental body water measures to properly quantify and identify changes in fluid balance, as well as measurement of food intake, metabolic rate, and related satiety hormones.

With reductions in size and improvements in portability of ultrasound technology, the identification of lung comet tails is a simple and robust way to detect extravascular lung water. ${ }^{47,48}$ Based on reports of the increased prevalence of high altitude pulmonary edema in children, ${ }^{17,49}$ as well as observations of an increased pulmonary artery systolic pressure in children at high altitude relative to adolescents and adults, ${ }^{13,14}$ we hypothesized that children would also have a larger lung comet tail score than adults at high altitude. Our hypothesis was not supported. Although high altitude pulmonary edema is a very rare condition with a prevalence proportional to the rate of ascent and the altitude achieved, affecting less than $1^{50}$ to $16 \%{ }^{51}$ of adults traveling between $2500 \mathrm{~m}$ and $5500 \mathrm{~m}$, our findings suggest that the development of extravascular lung water can be attenuated using a cautious ascent profile while traveling to moderate-high altitudes, albeit in a small sample of individuals. Furthermore, the absence of prolonged, strenuous exercise (ie, passive ascent) likely limited the increase in pulmonary artery pressure that would contribute to the development of extravascular lung water.

Despite differences in the development of AMS between children and adults, there were no differences in $\mathrm{S}_{\mathrm{p}} \mathrm{O}_{2}$ at any point throughout the trip. During acclimatization to high altitude, a progressive increase in alveolar ventilation increases the arterial pressure of $\mathrm{O}_{2}$ and $\mathrm{S}_{\mathrm{p}} \mathrm{O}_{2}$ over time, and this slow recovery of $\mathrm{S}_{\mathrm{p}} \mathrm{O}_{2}$ at the upper station was observed (and similar) in both groups. Importantly, this recovery of $\mathrm{S}_{\mathrm{p}} \mathrm{O}_{2}$ indicates that ventilatory acclimatization is indeed likely happening at a similar rate in children and adults. Furthermore, in both groups, there was no relation between $\mathrm{S}_{\mathrm{p}} \mathrm{O}_{2}$, change in $\mathrm{S}_{\mathrm{p}} \mathrm{O}_{2}$, and any symptom of AMS, ELW, or change in body weight on or between any days. We acknowledge that the cause of AMS is much more complex than can be explained by $\mathrm{S}_{\mathrm{p}} \mathrm{O}_{2}$ alone. ${ }^{52}$

\section{LIMITATIONS}

This work has limitations. It describes a very small sample size, across a broad maturational range and mixed sex. There is no questionnaire for AMS specifically for children (with the exception of pre-verbal children ${ }^{53}$ ) or adolescents, so differences in perception and self-reporting of symptoms between children and adults could have influenced the AMS scores. Our single-frequency measure of body water was limited, and we did not measure energy intake or water intake or have any direct measure of daily hydration status. 


\section{Conclusions}

During a stepped and passive ascent to high altitude, children, like adults, became symptomatic with acute increases in altitude, desaturated to a similar degree, and showed improvement with increasing time spent at altitude. Children became sick more frequently than adults, and children who developed AMS had more severe symptoms than adults with AMS and significantly more gastrointestinal-related symptoms. Importantly, weight loss at high altitude occurs sooner in children and occurs to a greater degree, driven largely by a loss in total body water. Awareness of AMS and strategies to maintain body weight and hydration are important for children traveling to high altitudes.

Acknowledgments: First and foremost, we thank all the families that took part in this research project. We thank Greg duManoir, Chris McNeil, Philip Ainslie, Christine Tallon, Dean Perkins, Sebastian Piombo, and Alyssa Koziol for assisting with data collection and logistical processes and sharing intellectual feedback throughout the process. We thank Syna MacLagan for creating a fun and stimulating environment for the children while traveling, and we thank the White Mountain Research Center staff for their cooking and hospitality. Special thanks to Audrey Kirby for lending her logistical expertise to the planning and coordinating of this international project.

Author Contributions Conception and design of study (MGR, MS, AMM); data collection (MGR, AMM, IAG, ARV, SRA); data interpretation (MGR, IAG, ARV, KJS, BS, AMM, MS); drafting (MGR, AMM); critical revision and approval of the final manuscript (all authors).

Financial/Material Support: MGR was supported by a research-intraining grant from the Wilderness Medical Society, supported by the Academy of Wilderness Medicine ${ }^{\circledR}$ and a NSERC PGS-D scholarship. AMM and KJS were supported by NSERC Discovery Grants.

Disclosures: None.

\section{References}

1. Theis MK, Honigman B, Yip R, McBride D, Houston CS, Moore LG. Acute mountain sickness in children at 2835 meters. Am J Dis Child. 1993;147(2):143-5.

2. Chan CW, Lin YC, Chiu YH, Weng YM, Li WC, Lin YJ, et al. Incidence and risk factors associated with acute mountain sickness in children trekking on Jade Mountain, Taiwan. J Travel Med. 2016;23(1):tav008

3. Moraga FA, Osorio JD, Vargas ME. Acute mountain sickness in tourists with children at Lake Chungará (4400 m) in northern Chile. Wilderness Environ Med. 2002;13(1):31-5.

4. Pollard AJ, Niermeyer S, Barry P, Bartsch P, Berghold F, Bishop RA, et al. Children at high altitude: an international consensus statement by an ad hoc committee of the International Society for Mountain Medicine, March 12, 2001. High Alt Med Biol. 2001;2(3):389-403.

5. Kriemler S, Radtke T, Burgi F, Lambrecht J, Zehnder M, BrunnerLa Rocca HP. Short-term cardiorespiratory adaptation to high altitude in children compared with adults. Scand J Med Sci Sport. 2016;26(2):147-55.

6. Meijer H, Jean D. Consensus statement of the UIAA Medical Commission: children at altitude. High Alt Med Biol. 2008;41(9):1-13.
7. Springer C, Barstow TJ, Cooper DM. Effect of hypoxia on ventilatory control during exercise in children and adults. Pediatr Res. 1989;25(3):285-90.

8. Marcus CL, Glomb WB, Basinski DJ, Davidson SL, Keens TG. Developmental pattern of hypercapnic and hypoxic ventilatory responses from childhood to adulthood. $J$ Appl Physiol. 1994;76(1):314-20.

9. Segar JL. Ontogeny of the arterial and cardiopulmonary baroreflex during fetal and postnatal life. Am $J$ Physiol. 1997;297(2):R457-71.

10. Leung J, Kosinski PD, Croal PL, Kassner A. Developmental trajectories of cerebrovascular reactivity in healthy children and young adults assessed with magnetic resonance imaging. $J$ Physiol. 2016;594(10):2681-9.

11. Wu C, Honarmand AR, Schnell S, Kuhn R, Schoeneman SE, Ansari SA, et al. Age-related changes of normal cerebral and cardiac blood flow in children and adults aged 7 months to 61 years. J Am Heart Assoc. 2016;5(1), e002657.

12. Takahashi T, Shirane R, Sato S, Yoshimoto T. Developmental changes of cerebral blood flow and oxygen metabolism in children. AJNR Am J Neuroradiol. 1999;20(5):917-22.

13. Allemann Y, Stuber T, de Marchi SF, Rexhaj E, Sartori C, Scherrer $\mathrm{U}$, et al. Pulmonary artery pressure and cardiac function in children and adolescents after rapid ascent to 3,450 m. Am J Physiol Heart Circ Physiol. 2012;302(12):H2646-53.

14. Kriemler S, Jansen C, Linka A, Kessel-Schaefer A, Zehnder M, Schürmann T, et al. Higher pulmonary artery pressure in children than in adults upon fast ascent to high altitude. Eur Respir $J$. 2008;32(3):664-9.

15. Scoggin CH, Hyers TM, Reeves JT, Grover RF. High-atitude pulmonary edema in the children and young adults of Leadville, Colorado. N Engl J Med. 1977;297(23):1269-72.

16. Hultgren HN, Marticorena EA. High altitude pulmonary edema. Epidemiologic observations in Peru. Chest. 1978;74(4):372-6.

17. Hultgren HN, Honigman B, Theis K, Nicholas D. High-altitude pulmonary edema at a ski resort. West J Med. 1996;164(3): $222-7$.

18. Milledge JS, Lahiri S. Respiratory control in lowlanders and Sherpa highlanders at altitude. Respir Physiol. 1967;2(3):310-22.

19. Severinghaus JW, Mitchell RA, Richardson BW, Singer MM. Respiratory control at high altitude suggesting active transport regulation of CSF pH. J Appl Physiol. 1963;18:1155-66.

20. Dempsey JA, Forster HV, Chosy LW, Hanson PG, Reddan WG. Regulation of CSF[HCO3-] during long-term hypoxic hypocapnia in man. J Appl Physiol Respir Environ Exerc Physiol. 1978;44(2): 175-82.

21. Meyer F, Bar-Or O, Salsberg A, Passe D. Hypohydration during exercise in children: effect on thirst, drink preferences, and rehydration. Int J Sport Nutr. 1994;4(1):22-35.

22. Fawkner SG, Armstrong N. Oxygen uptake kinetic response to exercise in children. Sports Med. 2003;33(9):651-69.

23. Winsley RJ, Fulford J, Roberts AC, Welsman JR, Armstrong N. Sex difference in peak oxygen uptake in prepubertal children. $J$ Sci Med Sport. 2009;12(6):647-51.

24. Roach RC, Hackett PH, Oelz O, Bärtsch P, Luks AM, MacInnis MJ, et al. The 2018 Lake Louise acute mountain sickness score. High Alt Med Biol. 2018;19(1):4-6.

25. Mirwald RL, Baxter-Jones ADG, Bailey DA, Beunen GP. An assessment of maturity from anthropometric measurements. Med Sci Sports Exerc. 2002;34(4):689-94.

26. Summerfield DT, Johnson DB. Lung ultrasound comets - technique and clinical significance. In: Hot Topics in Echocardiography. Rijeka, Croatia. 2016:51-64. 
27. Bloch J, Duplain H, Rimoldi SF, Stuber T, Kriemler S, Allemann Y, et al. Prevalence and time course of acute mountain sickness in older children and adolescents after rapid ascent to 3450 meters. Pediatrics. 2009;123(1):1-5.

28. Yaron M, Niermeyer S, Lindgren KN, Honigman B, Strain JD, Cairns CB. Physiologic response to moderate altitude exposure among infants and young children. High Alt Med Biol. 2003;4(1):53-9.

29. Wang L, Yin J, Nickles HT, Ranke H, Tabuchi A, Hoffmann J, et al. Hypoxic pulmonary vasoconstriction requires connexin 40mediated endothelial signal conduction. J Clin Invest. 2012;122(11):4218-30.

30. Pradhan S, Yadav S, Neupane P, Subedi P. Acute mountain sickness in children at 4380 meters in the himalayas. Wilderness Environ Med. 2009;20(4):359-63.

31. Kohler M, Kriemler S, Wilhelm EM, Brunner-LaRocca H, Zehnder M, Bloch KE. Children at high altitude have less nocturnal periodic breathing than adults. Eur Respir J. 2008;32(1):189-97.

32. Moraga FA, Pedreros CP, Rodríguez CE. Acute mountain sickness in children and their parents after rapid ascent to $3500 \mathrm{~m}$ (Putre, Chile). Wilderness Environ Med. 2008;19(4):287-92.

33. Kriemler S, Bürgi F, Wick C, Wick B, Keller M, Wiget U, et al. Prevalence of acute mountain sickness at 3500mwithin and between families :a prospective cohort study. High Alt Med Biol. 2014; 15(1):28-38.

34. Vats P, Singh VK, Singh SN, Singh SB. High altitude induced anorexia: effect of changes in leptin and oxidative stress levels. Nutr Neurosci. 2007;10(5-6):243-9.

35. Westerterp-Plantenga MS, Westerterp KR, Rubbens M, Verwegen CR, Richelet JP, Gardette B. Appetite at "high altitude" [Operation Everest III (Comex-'97)]: a simulated ascent of Mount Everest. J Appl Physiol (1985). 1999;87(1):391-9.

36. Westerterp KR, Kayser B. Body mass regulation at altitude. Eur J Gastroenterol Hepatol. 2006;18(1):1-3.

37. Rose MS, Houston CS, Fulco CS, Coates G, Sutton JR, Cymerman A. Operation Everest II: nutrition and body composition. J Appl Physiol (1985). 1988;65(6):2545-51.

38. Altman PL, Katz DD. Blood and Other Body Fluids. Washington, DC: Federation of American Societies for Experimental Biology; 1961.

39. Suh HG, Kavouras SA. Water intake and hydration state in children. Eur J Nutr. 2019;58(2):475-96.
40. Bar-Or O, Dotan R, Inbar O, Rotshtein A, Zonder H. Voluntary hypohydration in 10- to 12-year-old boys. J Appl Physiol Respir Environ Exerc Physiol. 1980;48(1):104-8.

41. Dünnwald T, Gatterer $H$, Faulhaber M, Arvandi M, Schobersberger W. Body composition and body weight changes at different altitude levels: a systematic review and meta-analysis. Front Physiol. 2019;10:430.

42. Rowland T, Hagenbuch S, Pober D, Garrison A. Exercise tolerance and thermoregulatory responses during cycling in boys and men. Med Sci Sports Exerc. 2008;40(2):282-7.

43. Brenner BM, Rector FC. Brenner \& Rector's The Kidney. 8th ed. Philadelphia, PA: Saunders Elsevier; 2008.

44. Hawkins WW, Speck E, Leonard VG. Variation of the hemoglobin level with age and sex. Blood. 1954;9(10):999-1007.

45. Leung AKC, Leung AAM, Wong AHC, Hon KL. Travelers' diarrhea: a clinical review. Recent Pat Inflamm Allergy Drug Discov. 2019;13(1):38-48.

46. Jaffrin MY, Morel H. Body fluid volumes measurements by impedance: a review of bioimpedance spectroscopy (BIS) and bioimpedance analysis (BIA) methods. Med Eng Phys. 2008;30(10):1257-69.

47. Wimalasena Y, Windsor J, Edsell M. Using ultrasound lung comets in the diagnosis of high altitude pulmonary edema: fact or fiction? Wilderness Environ Med. 2013;24(2):159-64.

48. Lichtenstein D, Mézière G, Biderman P, Gepner A, Barré O. The comet-tail artifact. An ultrasound sign of alveolar-interstitial syndrome. Am J Respir Crit Care Med. 1997;156(5):1640-6.

49. Durmowicz AG, Noordeweir E, Nicholas R, Reeves JT. Inflammatory processes may predispose children to high-altitude pulmonary edema. J Pediatr. 1997;130(5):838-40.

50. Sophocles Jr AM, Bachman J. High-altitude pulmonary edema among visitors to Summit County, Colorado. J Fam Pract. 1983;17(6):1015-7.

51. Bärtsch P. High altitude pulmonary edema. Respiration. 1997;64(6):435-43.

52. Turner REF, Gatterer H, Falla M, Lawley JS. High altitude cerebral edema: its own entity or end-stage acute mountain sickness? J Appl Physiol (1985). 2021;131(1):313-25.

53. Yaron M, Waldman N, Niermeyer S, Nicholas R, Honigman B. The diagnosis of acute mountain sickness in preverbal children. Arch Pediatr Adolesc Med. 1998;152(7):683-7. 